\title{
Fatty acids evolution and composition of olive oils extracted from different olive cultivars grown in Calabrian area
}

\author{
By Marco Poiana* and Antonio Mincione
}

\author{
Department of Biotecnologie per Monitoraggio Agro-alimentare ed Ambientale (BIOMAA). \\ Università Mediterranea di Reggio Calabria. p.zza S. Francesco da Sales, 4. \\ 89061 - Gallina - Reggio Calabria. Italy. E-mail:mpoiana@unirc.it
}

\section{RESUMEN}

Evolución y composición en ácidos grasos de aceites de oliva extraídos a partir de diferentes plantaciones de olivo cultivados en el área de Calabria.

Este trabajo muestra algunas peculiaridades de las composiciones en ácidos grasos de aceites extraídos de nueve plantaciones de olivo cultivados en Calabria. La zona de cultivo es típicamente olivícola. Las plantaciones estudiadas fueron: Cassanese, Coratina, Itrana, Leccino, Nociara, Ottobratica, Pendolino, Picholine y Sinopolese. Los aceites fueron extraídos por presión a partir de aceitunas recogidas en un período comprendido entre Octubre y Enero. Las observaciones fueron repetidas durante tres años consecutivos. La evolución del contenido en ácido oleico mostró una tendencia creciente en aceites de Cassanese, Itrana, Coratina, Sinopolese, Pendolino y Leccino. Los ácidos palmítico y linoleico mostraron una tendencia a disminuir durante la maduración en todos los aceites. En los muestreos de inicio de estación algunos aceites superaron los límites establecidos por la ley para el ácido linolénico. Mediante un análisis jerárquico de "cluster" se pueden localizar dos grupos principales de aceites. Los mismos resultados estadísticos se pueden conseguir considerando la relación oleico/linoleico. Esta relación fue constante durante todo el período de maduración.

PALABRAS-CLAVE: Aceite de oliva - Ácidos grasos - Análisis de "cluster - Cromatografía de gases - Maduración - Plantación

\section{SUMMARY}

Fatty acids evolution and composition of olive oils extracted from different olive cultivars grown in Calabrian area.

This work showed some peculiarities of fatty acids profile of nine olive cultivars cultivated in a typical olive growing Calabrian area. The cultivars studied were: Cassanese, Coratina, Itrana, Leccino, Nociara, Ottobratica, Pendolino, Picholine and Sinopolese. Oils were extracted by pressure from olives collected for a period of time comprised from October to January. The samplings were repeated for three years. The evolution of the oleic acid content showed an increasing trend in Cassanese, Itrana, Coratina, Sinopolese, Pendolino, and Leccino. Palmitic and linolenic acid showed a decrease in all the observed cultivar. Some cultivars in early ripe stage showed a higher linolenic acid content than the limit established legally. From a hierarchical cluster analyses two main groups were distinguished based on all fatty acid. The same statistical results were obtained considering the oleic/linoleic ratio only, that is a constant parameter throughout the olive ripening.

KEY-WORDS: Fatty acids - Gaschromatography - Olive oil - Ripening - Cultivar - Cluster analysis.

\section{INTRODUCTION}

The gas chromatographic analysis of fatty acid methyl esters is considered extremely useful for the characterization and quality control of olive oil. The main fatty acids in olive oil are those comprised between the myristic (14 carbon atoms) and lignoceric (24 carbon atoms). The most prominent are the monounsaturated oleic and palmitoleic, the polyunsaturated linoleic and linolenic. The approved limits for some of these have been published by European Union (European Community Regulation, 1991; 2001) and International Olive Oil Council and previously discussed by other researchers (Conte et al, 2000). The respect of these limits does not characterize olive oil (especially extra virgin and virgin as currently defined). Fatty acid composition differs from sample to sample. It is influenced by the olive variety, production zone, climate and stage of maturity of the drupes when they are collected.

Some studies have been carried out with the aim of characterizing particular productions of olive oil, which have given great importance to the fatty acid profile. The Italian production was investigated and characterized by Panelli and Montedoro (1988). They sampled the olives from eight cultivar introduced in Umbria during ripening and they measured the composition of fatty acids in the obtained oils. Parlati et al. (1995) reported a three year research on olive monocultivar oils of typical Calabrian olives and followed the evolution of fatty acids and sterolic composition and other qualitative indexes. A similar study was carried out by Frega et al. (1991) on the triglyceridic and fatty acid composition of olive oils from Leccino and Frantoio cultivars of Chiantis' country (Tuscany). Conte et al. (1993) characterized extra virgin olive oils produced in Emilia Romagna. Boschelle et al. (1994) studied the olive oils of the Trieste gulf by means of chemometric applications to the study of correlations between chemical and physical data. Koprivnjak and Conte (1996) measured the fatty acid composition of virgin olive oils from Pula (Croatia). De Leonardis et al. (1996) studied the composition of olive oils produced from cultivars grown in Molise (South of Italy). Spugnoli et al. (1998) characterized the fatty 
acid profile of some monovariety olive oils from Tuscany.

The fatty acid profile evolution of oils produced by typical Spanish olive cultivars like Picual and Hoijblanca (Gutierrez et al., 1999) and Moroccan Picholine (Ajana et al. 1998) has also been studied.

Several researchers have tried to correlate the geographical origin to the fatty acid composition in olive oil. Alonso Garcia and Aparicio Lopez (1993) have investigated the possibility of distinguishing among extra virgin olive oils produced in different regions of Spain, Italy and Portugal, through their fatty acid content. Tsimidou and Karalostas (1993) classified Greek virgin olive oils according to multivariate analyses of the fatty acid composition of the oils. Other researchers (Stefanoudaki et al, 2000) studied the characterization and authenticity of virgin oils extracted from the olive varieties Coratina (Italy), Picual (Spain) and Koroneki (Greece) matching sensory, physical, chemical and compositional data, within their fatty acid composition.

In a previous work, Poiana and Mincione (2003) investigated the triglyceride composition and evolution throughout olive ripening of nine cultivars grown in a typical Calabrian environment. Among the cultivars were the most common of this area (Ottobratica and Sinopolese), Calabrian type (Cassanese), and others introduced in Calabria from Italian regions. In this research work we depicted the fatty acid composition of the oils produced from these varieties and the evolution of these components during the ripening period resulting from a three year examination of the oils extracted.

\section{MATERIAL AND METHODS}

\subsection{Olive oil samples}

Olives were collected from certain trees of the cultivars which were determined subject matter of this work: Cassanese, Coratina, Itrana, Leccino, Nociara, Ottobratica, Pendolino, Picholine and Sinopolese. Samplings were carried out over a period of time from the beginning of October to the middle of January, at different dates alternating for time periods of 7-15 days. The sessions considered were:

- from 2 to 7 October

- from 11 to 18 October

- from 22 to 28 October

- from 4 to 11 November

- from 17 to 26 November

- from 5 to 19 December

- from 7 to 9 January

- 19 January only for the last samples collection of the Itrana cultivar.

Comparable sampling dates were selected for all the cultivars and the seasons. The samplings were repeated for three seasons at similar dates every year. The olive grove location was the same for all the cultivars and placed in a typical Calabrian olive area in the Gioia Tauro district. For every cultivar several trees (8-15) were chosen and about $15 \mathrm{Kg}$ of olive fruits were randomly collected from them for each sampling.

Oils were extracted using a laboratory scale mill of $10 \mathrm{Kg}$ capacity. After picking, the olives were immediately washed and crushed with a hammer crusher, the resulting paste was mixed at room temperature $\left(15-20^{\circ} \mathrm{C}\right)$ for 35 minutes and pressed using a hydraulic press with a continuous increase in pressure till of $35 \mathrm{MPa}$. After centrifugal separation of the oily must the oil was filtered and dehydrated before analysis.

\subsection{Fatty acids analysis}

The analyses of fatty acids were performed according to the official method of the European Community Regulation (1991). The olive oil samples were esterified in a methanol solution of $2 \mathrm{~N} \mathrm{KOH}$ for 30 minutes at $50^{\circ} \mathrm{C}$. The gaschromatographic analyses of fatty acid methyl esters were performed on a Perkin Elmer $\mathbf{8 6 0 0}$ gas chromatograph, equipped with a flame ionization detector: The column was a fused silica capillary coating wirh CP-WAX 52CB (Varian) length 25 meters, inner diameter $0.32 \mathrm{~m}$, film thickness 0.20 $\mathrm{m}$. Helium was the carrier gas at a flow rate of $\mathbf{1 . 5}$ $\mathrm{mL} / \mathrm{min}$. The column temperature program was: initially isotherm for $10 \mathrm{~min}$ at $140^{\circ} \mathrm{C}$, an initial programmed rate of $1^{\circ} \mathrm{C} / \mathrm{min}$ up to $160^{\circ} \mathrm{C}$, then a second rate of $2^{\circ} \mathrm{C} / \mathrm{min}$ up to $220^{\circ} \mathrm{C}$ and a final isotherm for $15 \mathrm{~min}$. The injector and flame ionization detector temperatures were $250^{\circ} \mathrm{C}$. Samples of $0.2 \mathrm{~L}$ were injected into the split mode with a split ratio of 1:10. The apparatus itself carried out recording and integration. The analyses were repeated in triplicate. The gas-chromatographic peaks were identified as corresponding fatty acid methyl esters by check of the elution order on the column and compared the retention times with those of pure standards. Results were expressed as peak area ratio percentage.

\subsection{Data processing}

Analytical data were treated by means of the statistical package STATISTICA release 5 (Statsoft Corp.). The average percentage concentration of the gaschromatographic fatty acid methyl ester peaks in the different oils was used as matrix elements for the cluster. The amalgamation was performed through complete linkage of the data and the measurements of the distances were Euclidean.

\section{RESULTS AND DISCUSSION}

\subsection{Fatty acid composition of the oils}

Table I shows the fatty acid composition of the oils extracted from the olive samples of the nine varieties 


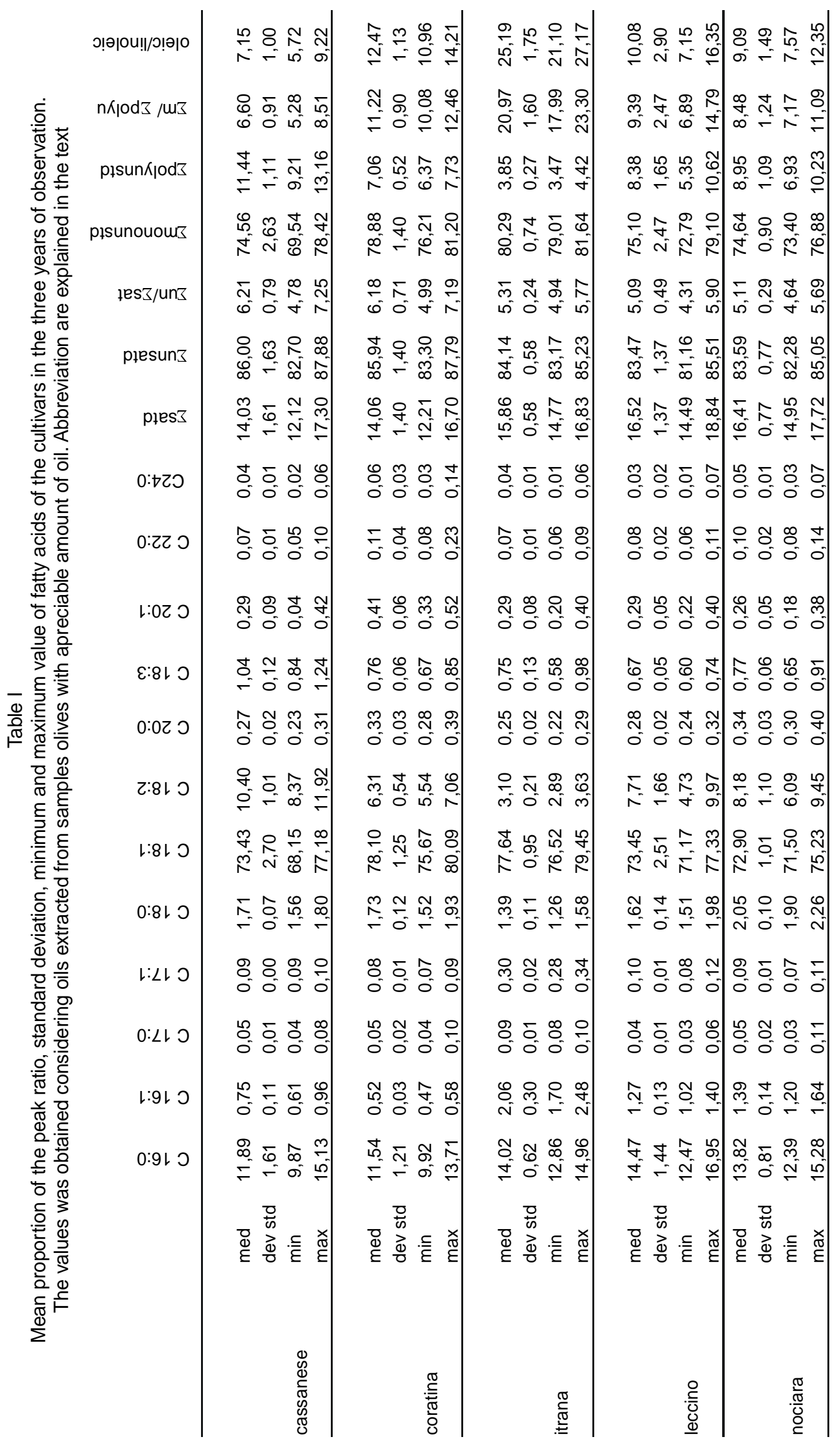




\begin{tabular}{|c|c|c|c|c|}
\hline ગ!ə|૦u!|/ગฺə| & 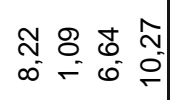 & 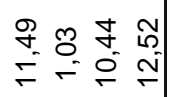 & 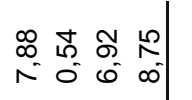 & 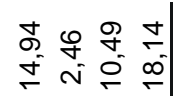 \\
\hline $\mathrm{n}$ א/od $3 / \mathrm{w}_{3}$ & 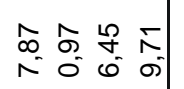 & 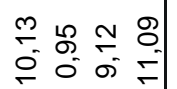 & 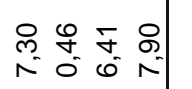 & 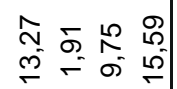 \\
\hline pisun $x_{j}$ od 3 & 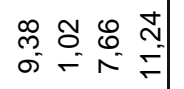 & 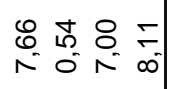 & 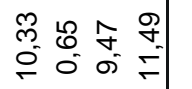 & 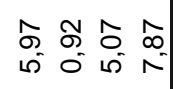 \\
\hline płsunouou 3 & 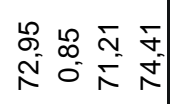 & 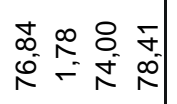 & 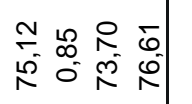 & $\begin{array}{l}\widetilde{0} \\
\stackrel{0}{N} \stackrel{0}{\circ}\end{array}$ \\
\hline fes z/un 3 & 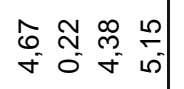 & 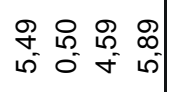 & 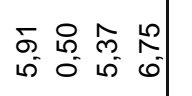 & 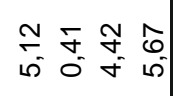 \\
\hline płesun 3 & 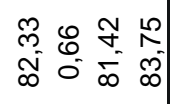 & 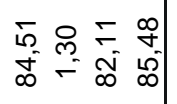 & 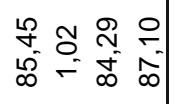 & 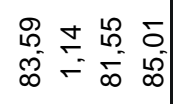 \\
\hline ples 3 & 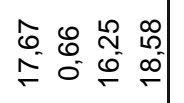 & 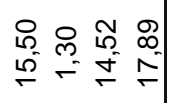 & 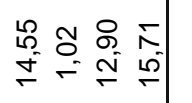 & 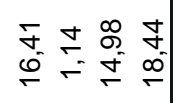 \\
\hline $0: \downarrow Z \supset$ & 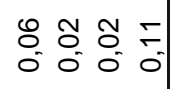 & $\begin{array}{llll} & 5 & 0 & 0 \\
0 & 0 & 0 & 0 \\
0 & 0 & 0\end{array}$ & 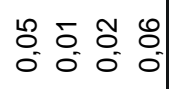 & 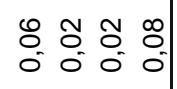 \\
\hline 0:ટટ ৩ & $\begin{array}{llll}L & 4 & 8 & 1 \\
0 & 0 & 0 & 0 \\
0 & 0 & 0\end{array}$ & $\begin{array}{llll}8 & 8 & 8 & 0 \\
0 & 0 & 0 & 0 \\
0 & 0 & 0 & 0\end{array}$ & 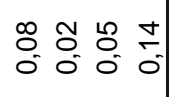 & 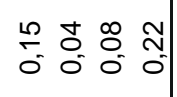 \\
\hline 1:02 & 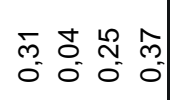 & 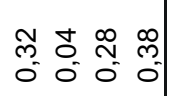 & 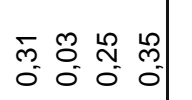 & 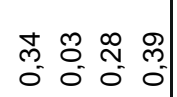 \\
\hline$\varepsilon: 810$ & 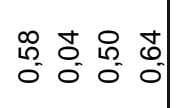 & 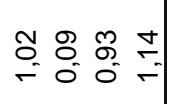 & 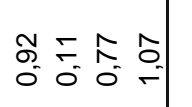 & $\begin{array}{lll}0 & 0 & 0 \\
& 0 & 0 \\
0 & 0 & 0 \\
0 & 0\end{array}$ \\
\hline 0:0乙 כ & 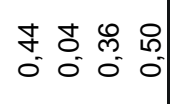 & 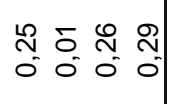 & 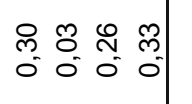 & 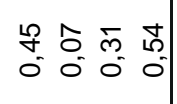 \\
\hline ट:81 ० & 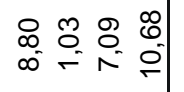 & 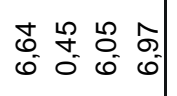 & 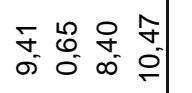 & 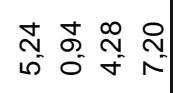 \\
\hline 1:81 0 & 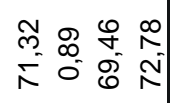 & 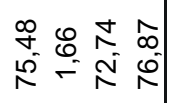 & 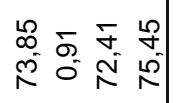 & 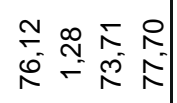 \\
\hline $0: 810$ & 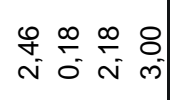 & 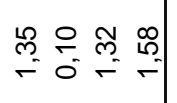 & 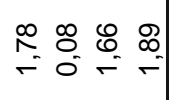 & 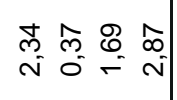 \\
\hline 1:L1 0 & 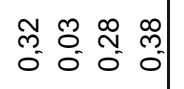 & 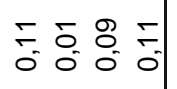 & $\begin{array}{cccc}\bar{E} & \overline{0} & 0 & \cdots \\
0 & 0 & 0 & 0 \\
0 & 0 & 0\end{array}$ & 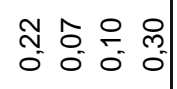 \\
\hline $0: \angle 10$ & 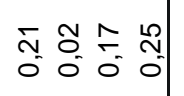 & $\begin{array}{llll} & \overline{0} & 0 & 8 \\
0 & 0 & 0 \\
0 & 0 & 0 \\
0\end{array}$ & $\begin{array}{llll}1 & 0 & 0 & m \\
0 & 0 & 0 & 0 \\
0 & 0 & 0 & 0\end{array}$ & $\begin{array}{lll}\forall & \theta & 0 \\
0 & 0 & 0 \\
0 & 0\end{array}$ \\
\hline 1:91 0 & 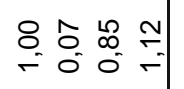 & 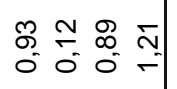 & 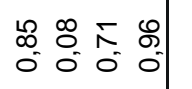 & $\begin{array}{ll}\text { t艹 } \\
0 \\
0\end{array}$ \\
\hline $0: 910$ & 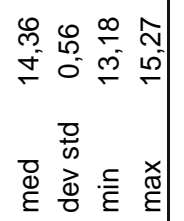 & 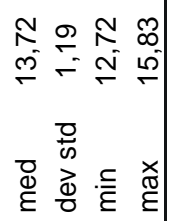 & 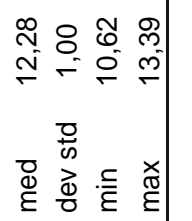 & 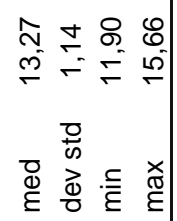 \\
\hline & 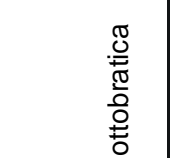 & 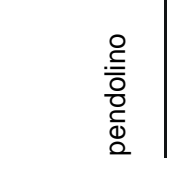 & 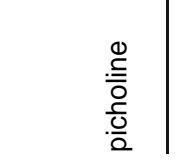 & $\begin{array}{l}\mathscr{D} \\
\frac{0}{0}\end{array}$ \\
\hline
\end{tabular}


studied. The mean proportion in percent of chromatographic areas was reported for each fatty acid separated by the gas chromatographic method, standard deviation and minimum and maximum values for each acid are also shown. In the same table several related indexes are also reported: the sum of unsaturated fatty acids, the sum of saturated fatty acids, the ratio between the first sum and the second, the sum of monounsaturated fatty acids, the sum of polyunsaturated fatty acids and their relative relationship, and the oleic to linoleic fatty acid ratio. These values were obtained by GC analysis of the fatty acid methyl esters of the oils extracted from the olives collected during their growth stages.

The composition shown on the table was derived only considering the samples of oil obtained by olives with a percentage of oil above an appreciable amount. This minimum limit was considered to be $80 \%$ of the average amount measured in the three seasons. This threshold content of the considered oil for every single cultivar was specific for each of them and in detail: Cassanese (7.1\%), Coratina (10.1\%), Itrana (10.7\%), Leccino (14.7\%), Nociara (11.7\%), Ottobratica (12.5\%), Pendolino (6.0\%), Picholine $(10.4 \%)$, Sinopolese $(11.5 \%)$. These amounts were considered in accordance with an average-yield normally obtained in crops of the same cultivars in analogous areas.

In all the oils analyzed the myristic acid was found to be less than $0.01 \%$ (as area percent) of the total fatty acids quantified. So, all the samples fell inside the legal limits imposed by the European Regulation (1991) which establishes a maximum level of tetradecanoic acid of $0.05 \%$ in the olive oils. Considering the European regulation, some notation must be made about the content of linolenic acid in some mono-cultivar olive oils. The maximum limit for this fatty acid is $0.9 \%$, but in the oils of Cassanese, Pendolino and Picholine the average percentage of the linolenic acid was higher. The other fatty acids, for which maximum limits are imposed by European law, were normally represented within the limits.

In comparison to the data reported by Parlati et al. (1995) some discrepancies were observed. These authors found a mean content of palmitic, palmitoleic and linoleic acid in Cassanese oils lower than that measured in this work during the 1995-1998 seasons. The same previously mentioned authors, in the oils of the Ottobratica cultivar in the years 1992-1994, observed a lower content of palmitic and oleic acid and a higher content of linoleic acid in comparison to those reported in this work. Sinopolese fatty acid composition was in good agreement. The differences for the Cassanese cultivar could be due to the different geographical areas of observation. Parlati et al. (1995) studied the Cassanese characteristics in its main area of diffusion, which is situated in the northern part of
Calabria region. The differences ascribed to the Ottobratica cultivar could be clarified as seasonal trends.

In regards to stearic acid content, it is possible to conclude that the most abundant content of this fatty acid was measured in oils of typical Calabrian cultivars as Ottobratica and Cassanese. This observation is in perfect agreement with Alonso Garcia and Aparicio Lopez (1993), who noticed an high stearic acid content as a common characteristic of Calabrian olive oil.

Considering the percentage value found by other authors, a great environmental influence can be observed. The cultivar Leccino (an ubiquitous one) showed evidence of the differences in the composition found in olive oils produced in Calabria, here reported, and the oils from Croatia (Koprivnjak and Conte, 1996), Molise (De Leonardis et al., 1996), and Tuscany (Frega et al., 1991).

Coratina showed the highest amount of oleic acid. In the oils from this cultivar, this fatty acid was on average $78 \%$ of the total (as chromatographic area per cent). In the three years of observation, Ottobratica showed the lowest mean of this fatty acid, which was $71.3 \%$. In these two cultivars variability was very low: the standard deviations shown by the oleic acid content were less than 0.9 in Ottobratica oils and about 1.3 in Coratina ones. In all the studied cultivar the dispersion from the mean values of this fatty acid was very small, in fact, with exception of Cassanese and Leccino oils, the standard deviations were less than 1.7.

The second most important fatty acid, in percentage content, is palmitic. In Leccino oils it was quantified to the greater mean amount of area proportion of the peaks $(14.5 \%)$, while in Coratina it was to the lower one (11.5\%). Contents of $14 \%$ and higher were measured in the mono-cultivar oils of Ottobratica (14.4\%) and Itrana (14.0\%).

Linoleic acid content is very interesting for the characterization of the oils. The Cassanese samples showed the greatest content: the average of this fatty acid was measured to $10.4 \%$. The least amount was quantified in Itrana oils, in which linoleic acid was on the average $3.1 \%$ with a range of $2.9-3.6 \%$. These values are very low and are lower than proposed by IOOC and FAO-CODEX Alimentarius. Boschelle et al. (1994) also found low levels of this fatty acid in olive oils produced near Trieste (north-east of Italy), which should confirm the very low content of linoleic acid in the oils extracted from Itrana olives.

\subsection{Evolution of fatty acids during drupe maturation}

Figures 1-5 depict the course of the main fatty acids present in the oil during drupe maturation. Figure 1 reports the evolution of the oleic acid 


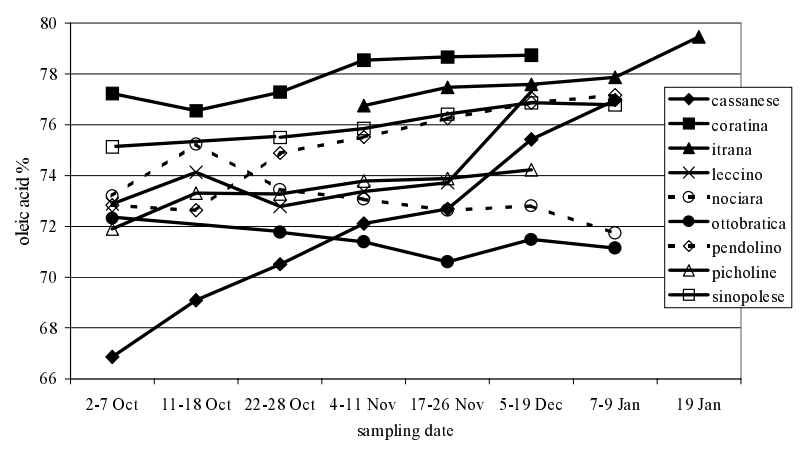

Figure 1

Evolution of oleic acid peak area percentage during ripening in the oils of the cultivars studied.

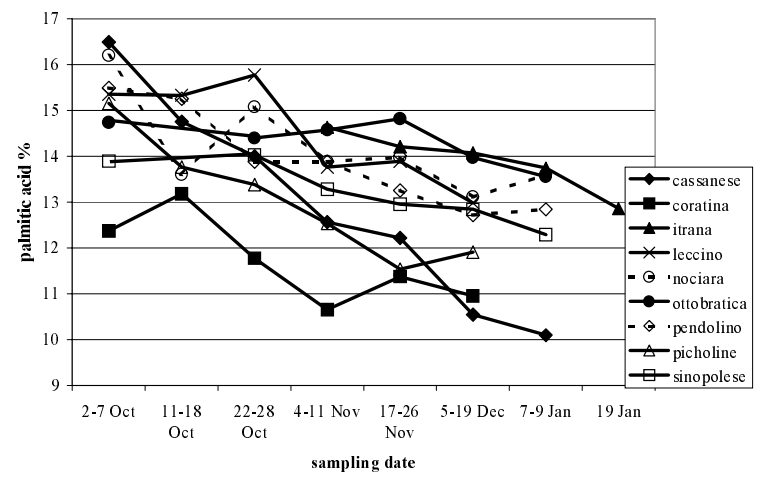

Figure 2

Evolution of palmitic acid peak area percentage during ripening in the oils of the cultivars studied.

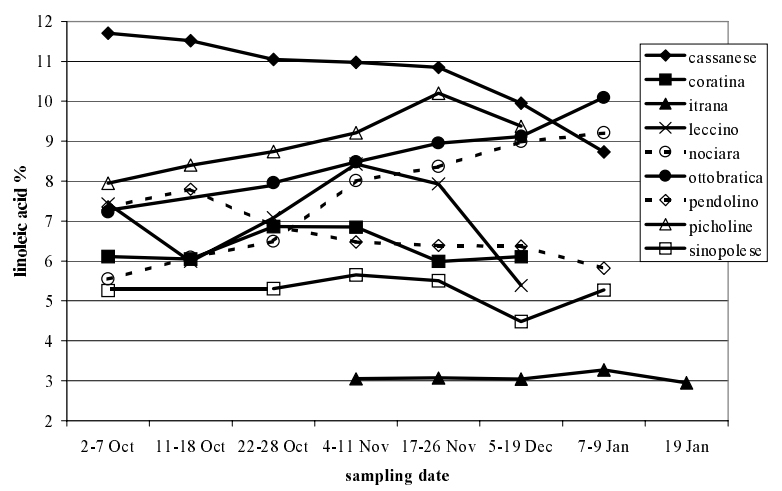

Figure 3

Evolution of linoleic acid peak area percentage during ripening in the oils of the cultivars studied.

contained in the extracted oils during the three seasons observed. An uniform trend was not measured for all the olive cultivars. The oils of Cassanese showed the largest enhancement from the first sample collected at the beginning of October (when the oleic acid was measured near $67 \%$ as area ratio of the total fatty acids presented in the oil) to the oil sampled on 7-9 of January in which the same fatty acid amounted to $77 \%$. This constant increase was reproducible for all three observed seasons. The content values reported were obtained through the average of the evaluations of the three years, and showed a very low standard deviation between 0.3 and 0.8 (data not reported here). In addition, the oils obtained from olives of the cultivars Itrana, Coratina, Sinopolese, Pendolino, and Leccino showed an increasing trend in their oleic acid content. In these cultivars the discrepancies were not as noticeable as in the oils extracted from Cassanese. From the first samples collected at the beginning of October to the last ones collected in January, an increase of $2 \%$ was observed. Moreover, the trends were not constant, great standard deviations were sometimes observed and, in some cases, the index of dispersion reached 1.4. This fact took to an oscillating trend as for Coratina in which, considering the three year average, the second sample showed a smaller content of oleic acid with respect to the first. The Coratina samplings at the middle of October highlighted a standard deviation of 1.4. This variability among the three years is probably due to pathologic and climatic effects and a consequent fall of fruits. An analogous explanation could be made for

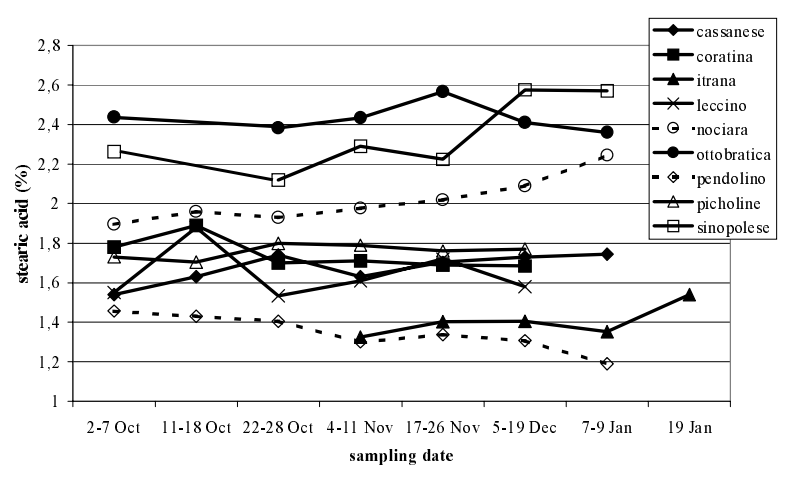

Figure 4

Evolution of stearic acid peak area percentage during ripening in the oils of the cultivars studied.

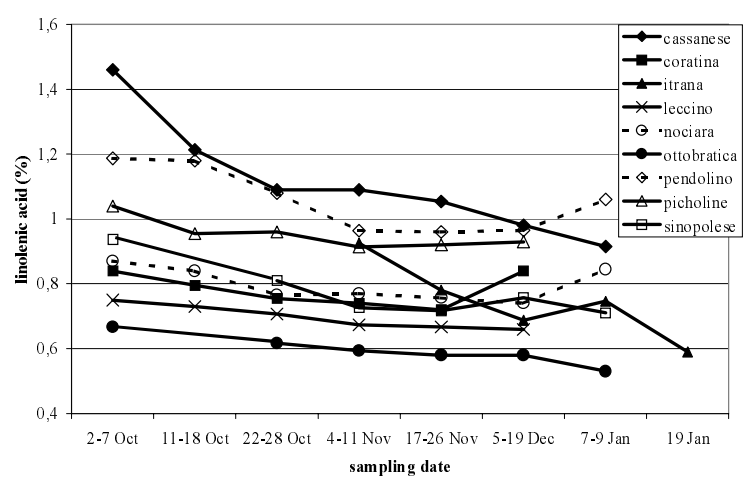

Figure 5

Evolution of linolenic acid peak area percentage during ripening in the oils of the cultivars studied. 
the oleic acid content in the Leccino oils. The fatty acid content was constant between the first sample and that extracted at the end of November, and then an increase, from $73.7 \%$ to $77.3 \%$, was measured. In this case a variability was observed particularly in the samples produced in November (standard deviation of $2.3-2.9$ ). These cultivars, Coratina and Leccino, showed a high content of infested drupe in some samplings, explained by the composition variability. More regularity in the increase of oleic acid was seen in the oils of Itrana, Pendolino and Picholine. Ottobratica oils showed a constant percentage amount of the oleic acid content for all the samplings, this fatty acid remained within $71-72 \%$. The oils extracted from Nociara olives indicated a decreasing trend of oleic acid, the sample obtained at the middle of October had oleic acid at $75.2 \%$, and in January the acid was at a mean of $71.7 \%$.

Figure 2 reports the course of the palmitic acid content in the oils extracted from olives collected at different times of ripening. In accordance with other researchers (Frega et al., 1991; Ajana et al., 1998; Gutierrez et al., 1999) this fatty acid presented a decline in its content during the period observed for all the extracted oils. Possibly, related to the oleic acid content, the Cassanese oils showed the greatest decrease: at the beginning of October the hexadecanoic acid was measured at $16.5 \%$ of the total fatty acids, and fell to nearly $10 \%$ in the oils extracted on January 7-9. The oils of Picholine also presented a marked decrease, in the first sample the palmitic acid was $15.2 \%$ and at the end of November it was $11.5 \%$. The other cultivars showed analogous trends even if they were less noticeable. The palmitic acid of Itrana oils was $14.6 \%$ of the total at the beginning of November and less than $13 \%$ in January. In Leccino oils, the same fatty acid decreased from 15.3 to $13 \%$ throughout the period from October to December. Pendolino exhibited a reduction from $15.5 \%$ to $12.9 \%$. A lower decrease, and sometimes with an oscillating trend, was measured for the palmitic acid content in Ottobratica, Sinopolese and Coratina. Particularly, in the last two cultivars, high standard deviations were measured for the three years of observation. This fact, as mentioned above for oleic acid, could be due to climatic and physiopathological conditions which caused an early drop of the drupes with the consequence of less ripe ones remaining on the tree and altering their oil composition.

The content (as area proportion of the chromatographic peaks) of linoleic acid in the oils extracted from the olives collected at different stages of ripening and different cultivars is depicted in figure 3 . In this figure it is possible to appreciate the different behaviors in the olive cultivars studied. Cassanese and Pendolino showed a decreasing trend, the first one from $11.7 \%$ to $8.7 \%$ (October-November), the second from 7.4 to $5.8 \%$ during the same period. The repeatability was very good during the three years (standard deviation for the observations was always less than 0.6 for these cultivars). On the contrary, the linoleic acid content in the oils of Nociara, Ottobratica and Picholine increased during the ripening of the olives. This acid was $7.2 \%$ in the Ottobratica oil obtained in the first sample in October and it became more than $10 \%$ in January. Nociara oils showed a great increase, in fact, their linoleic acid content was $5.6 \%$ in the October oils and $9.2 \%$ in those extracted in January. The cultivars Leccino and Coratina presented a maximum level of linoleic acid content in the middle of the observed period (end of October beginning of November). For these two cultivars the trend showed a fairly good repeatability over the three years studied, the standard deviations for Coratina observations were even less than 0.3 , more variability was measured for Leccino. A constant level of linoleic acid was shown by Itrana and Sinopolese with values comprised for the first cultivar between 3.0 and $3.3 \%$ and for the second between 4.5 and $5.7 \%$. The behavior of linoleic acid in monovarietal olive oils reported in the literature are in some disagreement with those reported here. Gutierrez et al. (1999), reported an increase for Picual and Hoijblanca, Ajana et al. (1998) observed an oscillating trend for Moroccan Picholine and the same fact was found by Pannelli and Montedoro (1988) for some olive oils produced in Umbria (central Italy).

Stearic acid showed a different trend throughout olive ripening for the nine observed cultivars. As notable in figure 4, the oils extracted from Nociara olives showed a constant increase from October to January, the content of stearic acid was $1.9 \%$ on October 2-7 and 2.3\% in January. These data were constantly repeatable in all the seasons of sampling. Itrana oils showed a slight increase. Similar to this behavior was that of the Cassanese oils, in which the stearic acid rose from $1.5 \%$ in the first sample to $1.8 \%$ in the last one (olives collected in January). Sinopolese oils presented an increase in the last part of the ripening period, and in fact, from the end of October to the middle of December this fatty acid reached a percentage of nearly 2.6. A slight decrease was measured in the content of stearic acid in the oils of Pendolino. The other cultivars had a constant content or an oscillating trend during ripening.

In accordance with other works previously reported, the linolenic acid content decreased throughout the ripening of the olive drupe. This tendency is depicted in figure 5 for the cultivars subjected to these observations. As previously described for other fatty acids, the linolenic acid content in the Cassanese oils also showed a clear variation throughout ripening. The linolenic decrease 
ranged from $1.5 \%$, measured in the oil extracted from olives collected at the beginning of October, to $0.9 \%$ found in January oils. With respect to the maximum level, it must be noted that the Cassanese oils had the tendency to overcome this value for a high proportion of the ripening period.Only when the drupes were fully ripe was this parameter at its limit. A similar decreasing trend was observed during the ripening of the cultivar Pendolino. Linolenic acid in the oil produced from its olives sampled in October was $1.1 \%$, in the oil produced from drupes collected in November the acid was slightly below 1\%. Itrana oils contained linolenic acid at $0.9 \%$ at the beginning of November and at $0.6 \%$ at the middle of January. Slight decreases during drupe ripening were observed for the oils of Picholine (from 1.04\% to $0.93 \%)$, Sinopolese $(0.94-0.71 \%)$, Leccino (0.75-0.66\%), Ottobratica (0.67-0.53\%). Nociara and Coratina showed an increase of linolenic content in their oils in the last samples (December and January).

The content of the fatty acid evolutions observed were fairly consistent with the results reported in the literature as in some cases previously clarified. The trends of palmitic, stearic and linolenic acid of Cassanese, Sinopolese and Ottobratica oils agreed with those performed by Parlati et al. (1995). The observations carried out in this study for linoleic and oleic acid in Ottobratica oils do not fit very well with those of the authors previously cited, which is probably due to the small number of observation periods (only two per year) carried out by Parlati et al. (1995). Moreover, this cultivar shows a long period of full ripeness of the drupe, and, in particular seasons, it is very vulnerable to physiopathologies that could result in the dropping of drupes and consequently the variation in fatty acid profile.

Trends in the index derived from the ratio between unsaturated and saturated fatty acids are not very clear (figure 6). An evident increase throughout the ripening of the olives was only observed in Cassanese and Picholine oils. The Cassanese oils exhibited this change as consequence of the marked trends of the main fatty acids, as previously it has been described. Pendolino and Itrana oils presented a lower increase of this ratio. The other cultivars showed a tendency to increase the index, albeit this orientation was not so distinct.

The monounsaturated to polyunsaturated fatty acid ratio is heterogeneous among the different cultivars (Figure 7). Only the Cassanese oils showed a constant increase in the ratio during the sampling (from October to January). On the contrary, Ottobratica and Picholine oils showed a constant decrease, while the other mono-cultivar oils showed oscillating trends.

The oleic/linoleic ratio is an index that remained quite constant throughout the ripening in all the observed cultivars. Only Cassanese showed a slight decrease, and an opposite trend was detected in Picholine oils.

\subsection{Cluster analysis}

Figure 8 reports a hierarchical cluster analysis using the mean fatty acid composition of the analyzed oils as component matrix. In a similar manner of the observed cluster distribution using triacylglycerol as the variable studied, the same two main groups were observed. This is possibly due to a no-scaling of the considered variables, so the variables with a higher value had greater importance in the construction of the cluster. Therefore the same result was obtained only considering the most important fatty acids such as oleic, palmitic, linoleic, stearic, and linolenic.

A strong affinity was noticed between the oils of Nociara and Leccino, and between those of Picholine and Cassanese. These four cultivars together with Ottobratica formed one cluster. The second cluster was composed by Sinopolese, Pendolino, Coratina and Itrana. The affinity of the different cultivars was also expressed by their oleic/linoleic ratio. The two main clusters were well

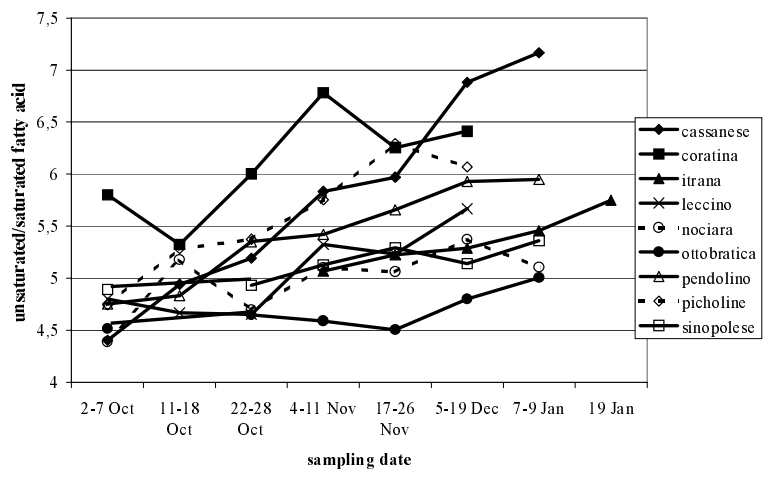

Figure 6

Evolution of unsaturated/saturated fatty acid ratio during ripening in the oils of the cultivars studied.

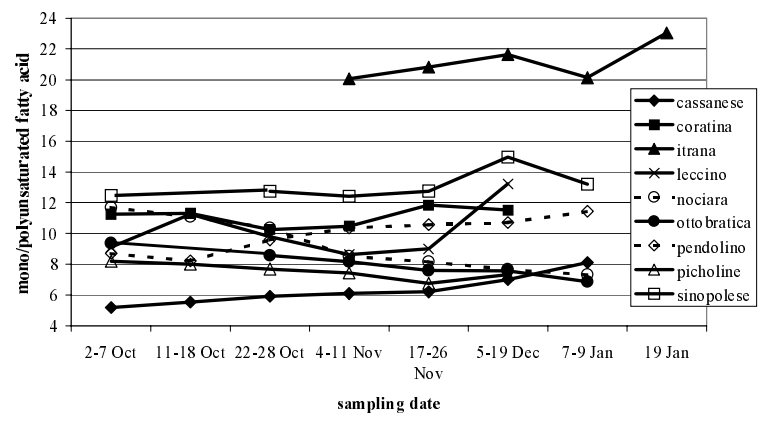

Figure 7

Evolution of monounsaturated/polyunsaturated fatty acid ratio during ripening in the oils of the cultivars studied. 


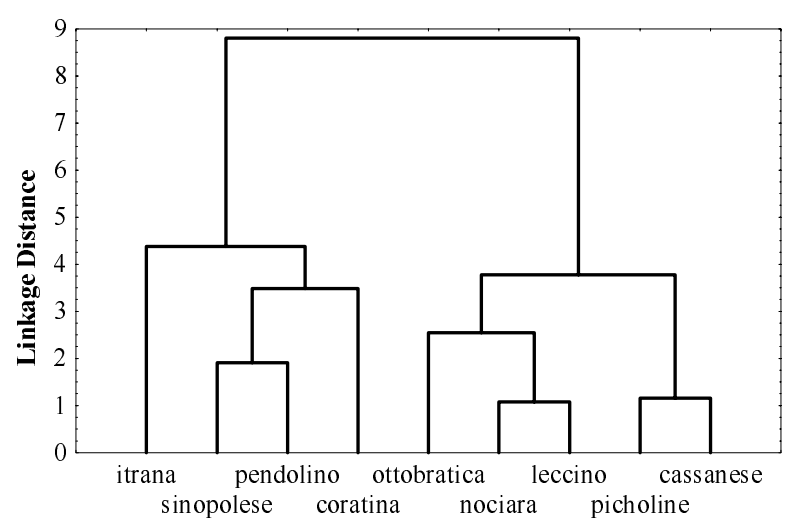

Figure 8

Dendrogram of olive oils obtained from cluster analyses. Euclidean distances.

reflected and the cultivars were separated into two groups: one with a ratio of 10 and the other with a higher ratio. This is very interesting because, contrary to the trend of the main fatty acids, the oleic/linoleic ratio was constant throughout ripening and so it could become a cultivar characteristic.

\section{CONCLUSIONS}

This work outlines some peculiarities of the fatty acid contents of the monocultivar oils extracted from olives of nine cultivars cultivated in an area pertaining to olive growing. The fatty acid trends showed characteristics typical of the cultivar considered. Palmitic and linolenic acids showed decreases in all the cultivars observed. In most of the cultivars oleic acid exhibited an increasing trend but in others particular trends were followed. These characters were very important in the fatty acids considered for a market classification of olive oils. Some cultivars in early ripe stage showed no respect for the imposed limits for the linolenic acid.

From a hierarchical cluster analysis two main cluster groups were distinguished based on all fatty acid. Similar results were obtained pasting the content of the main fatty acids and also considering only the oleic to linoleic acid ratio which is a constant parameter throughout olive ripening.

In conclusion the peculiar composition and evolution of fatty acids was typical of each cultivar, and is very important for the classification of the olive oil derived.

\section{BIBLIOGRAPHY}

Ajana H., El Antarl A., Hafidi A. 1998. Fatty acids and sterol evolution during the ripening of olives from the Moroccan Picholine cultivar. Grasas y Aceites, 49, 405-410.
Alonso Garcia M. V., Aparicio Lopez R. 1993. Characterization of European virgin olive oils using fatty acids. Grasas y Aceites, 44, 18-24.

Boschelle O., Giomo A., Conte L., Lercker, G. 1994. Chemometric applications to the study of correlations between chemical-physical data for characterization of olive cultivars from Trieste gulf. Riv. italiana Sost. Grasse, 71, 57-65.

Conte L. S., Caboni M. F., Lercker, G. 1993. Olive oil produced in Romagna. 2: oils from Rimini's area. Riv. italiana Sost. Grasse, 70, 249-251.

Conte L. S., Bortolomeazzi R., Moret S., Pizzale L., Vichi S. 2000. Recenti acquisizioni acquisizioni analitiche per la valutazione della della qualità, genuinità e stabilità dei grassi alimentari. Riv. italiana Sost. Grasse, 77, 431-438

De Leonardis A., De Felice M., Macciola V. 1996. Fatty acid composition of extra virgin olive oils from the lower Molise region. Riv. italiana Sost. Grasse, 73, 321-325.

European Community Regulation. 1991. Official Journal of European Community, L248, September $5^{\text {th }}$.

European Community Regulation. 2001. Official Journal of European Community, L201, July $26^{\text {th }}$.

Frega N., Bocci, F., Lercker G. 1991. Lipid composition of olive drupes from two cultivars of Chiantis' country during the ripening. Note I: triglyceride and fatty acid compositions. Riv. italiana Sost. Grasse, 68, 69-74.

Gutierrez F., Jimenez B., Ruiz A., Albi, M. A. 1999. Effect of olive ripeness on the oxidative stability of virgin olive oil extracted from the varieties Picual and Hojiblanca and on the different components involved. J. Agric. Food Chem., 47, 121-127.

Koprivnjak O., Conte L. S. 1996. Composition of hydrocarbon fraction and fatty acids of virgin olive oils from Pula area (Croatia). Riv. italiana Sost. Grasse, 73, 317-320.

Panelli G., Montedoro G. F. 1988. Scelte varietali, condizioni pedoclimatiche, maturazione del frutto e caratteristiche qualitative dell'olio di oliva. Conference Proceeding "Aspetti fisiologici della cascola, della maturazione, della conservazione e della trasformazione post-raccolta dei frutti". Turin (Italy) 3-4 October 1988, pag 99-105.

Parlati M. V., Perri E., Palopoli A., Rizzuti B., Pellegrino M. 1995. The qualitative characteristics of monovarietal oils produced in Calabria. Conference Proceeding "L'olivicoltura mediterranea: stato e prospettive della coltura e della ricerca". Rende - Cosenza (Italy) 26-28 January 1995, pag 681-686.

Spugnoli P., Parenti A., Cardini D., Modi G., Caselli S. 1998. Characterization of single variety extra virgin olive oils of three cultivars from Tuscany. Riv. italiana Sost. Grasse, 75, 227-233.

Stefanoudaki E., Kotsifaki F., Koutsaftakis A. 2000. Sensory and chemical profiles of three European olive varieties (Olea europea L.); an approach for the characterisation and authentication of the extracted oils. J. Sci. Food Agric., 80, 381-389.

Tsimidou M., Karakostas K. X. 1993. Geographical classification of Greek virgin olive oil by non-parametric multivariate evaluation of fatty acid composition. J. Sci. Food Agric., 62, 253-257.

Recibido: Febrero 2003 Aceptado: Febrero 2004 